\title{
Soya products and serum lipids: a meta-analysis of randomised controlled trials
}

\author{
Oluwabunmi A. Tokede ${ }^{1,2 *}$, Temilola A. Onabanjo ${ }^{3}$, Alfa Yansane $^{2}$, J. Michael Gaziano ${ }^{1,2,4}$ and \\ Luc Djoussé $1,2,4$ \\ ${ }^{1}$ Department of Medicine, Brigham and Women's Hospital, Boston, MA 02120, USA \\ ${ }^{2}$ Harvard School of Dental Medicine, Boston, MA 02115, USA \\ ${ }^{3}$ Jacobi Medical Center, Albert Einstein College of Medicine, Bronx, NY 10461, USA \\ ${ }^{4}$ Massachusetts Veterans Epidemiology and Research Information Center and Geriatric Research, Education and Clinical \\ Center, Boston Veteran Affairs Healthcare System, Boston, MA 02130, USA
}

(Submitted 25 November 2014 - Final revision received 6 May 2015 - Accepted 9 June 2015 - First published online 13 August 2015)

\begin{abstract}
Soya proteins and isoflavones have been reported to exert beneficial effects on the serum lipid profile. More recently, this claim is being challenged. The objective of this study was to comprehensively examine the effects of soya consumption on the lipid profile using published trials. A detailed literature search was conducted via MEDLINE (from 2004 through February 2014), CENTRAL (The Cochrane Controlled Clinical Trials Register) and ClinicalTrials.gov for randomised controlled trials assessing the effects of soya on the lipid profile. The primary effect measure was the difference in means of the final measurements between the intervention and control groups. In all, thirty-five studies (fifty comparisons) were included in our analyses. Treatment duration ranged from 4 weeks to 1 year. Intake of soya products resulted in a significant reduction in serum LDL-cholesterol concentration, $-4.83(95 \% \mathrm{CI}-7 \cdot 34,-2 \cdot 31) \mathrm{mg} / \mathrm{dl}$, TAG, $-4.92(95 \% \mathrm{CI}-7 \cdot 79,-2 \cdot 04) \mathrm{mg} / \mathrm{dl}$, and total cholesterol (TC) concentrations, $-5.33(95 \%$ CI $-8 \cdot 35,-2 \cdot 30) \mathrm{mg} / \mathrm{dl}$. There was also a significant increase in serum HDL-cholesterol concentration, $1.40(95 \%$ CI $0.58,2.23) \mathrm{mg} / \mathrm{dl}$. The $I^{2}$ statistic ranged from 92 to $99 \%$, indicating significant heterogeneity. LDL reductions were more marked in hypercholesterolaemic patients, $-7 \cdot 47(95 \% \mathrm{CI}-11 \cdot 79,-3 \cdot 16) \mathrm{mg} / \mathrm{dl}$, than in healthy subjects, $-2 \cdot 96(95 \% \mathrm{CI}-5 \cdot 28$, $-0.65) \mathrm{mg} / \mathrm{dl}$. LDL reduction was stronger when whole soya products (soya milk, soyabeans and nuts) were used as the test regimen, -11.06 $(95 \%$ CI $-15.74,-6.37) \mathrm{mg} / \mathrm{dl}$, as opposed to when 'processed' soya extracts, $-3.17(95 \% \mathrm{CI}-5 \cdot 75,-0.58) \mathrm{mg} / \mathrm{dl}$, were used. These data are consistent with the beneficial effects of soya proteins on serum LDL, HDL, TAG and TC concentrations. The effect was stronger in hypercholesterolaemic subjects. Whole soya foods appeared to be more beneficial than soya supplementation, whereas isoflavone supplementation had no effects on the lipid profile.
\end{abstract}

Key words: Hypercholesterolaemia: Lipids: Nutrition: Prevention: Heart disease

Dyslipidaemia is a primary risk factor for CVD, peripheral vascular disease and stroke. The WHO estimates that over $60 \%$ of CHD and $40 \%$ of ischaemic stroke in developed countries are due to total blood cholesterol levels in excess of the theoretical minimum of $3.8 \mathrm{mmol} / \mathrm{l}^{(1)}$. Reduction of serum LDL-cholesterol by about $5-6 \%^{(2)}$ has the potential to reduce CHD risk by $7-12 \%{ }^{(3)}$, whereas a $3 \%$ increase in HDL-cholesterol has the potential to lower the risk by $6-9 \%{ }^{(4,5)}$. Fasting serum TAG elevations also increase the risk for $\mathrm{CHD}^{(6)}$. The aggregate changes in these three lipoprotein risk factors can, therefore, potentially reduce $\mathrm{CHD}$ risk by $12-20 \%{ }^{(7)}$. As a result, cholesterol is by far the most studied risk factor for CHD risk ${ }^{(8)}$.

Although what constitutes an optimal dietary regimen remains a matter of controversy, current guidelines recommend diet as a first-line therapy for patients with elevated blood cholesterol concentrations ${ }^{(9)}$. Among the foods being suggested to lower blood lipids are soya products. A meta-analysis published in 1995 concluded that soya protein intake is effective in reducing total cholesterol (TC), LDL-cholesterol and TAG and in increasing HDL-cholesterol ${ }^{(10)}$. Following this, in October 1999, the US Food and Drug Administration approved labelling of foods containing soya protein as protective against $\mathrm{CHD}^{(11)}$; the American Heart Association released a similar advisory shortly thereafter ${ }^{(12)}$. The UK Joint Health Claims Initiative also permitted that the inclusion of at least $25 \mathrm{~g}$ of soya protein/ $d$ as part of a diet low in saturated fat can help reduce blood cholesterol'. Similar claims were also made in South Africa, the Philippines, Brazil and Indonesia ${ }^{(13)}$. All these

Abbreviation: TC, total cholesterol.

* Corresponding author: O. A. Tokede, fax +617 525 7739, email oluwabunmi_tokede@hms.harvard.edu 
presuppose that the hypolipidaemic effects of soya are due to its soya protein content. Soya products in addition, however, contain isoflavones, which have also been subjects of considerable scientific enquiry. Reports of trials investigating the effect of soya isoflavones on blood lipids have not been consistent $^{(14)}$.

Over a 100 randomised controlled trials (RCT) and ten metaanalyses have already been published, which have examined the effects of soya protein and/or isoflavones on lipids. Most of these studies report varying effects of soya proteins and/or soya isoflavones on blood cholesterol. Perhaps the only consensus on the subject is that consumption of soya products may have a more marked hypolipidaemic effect in hypercholesterolaemic individuals than in normocholesterolaemic subjects. Although the ten previously completed meta-analyses have reported beneficial effects of soya protein and/or isoflavone on serum lipids, this favourable effect is being challenged, and a reason may be because some recently completed trials do not report an effect of soya protein on serum lipids. In 2012, the European Food Safety Authority concluded that 'a cause and effect relationship has not been established between the consumption of isolated soya protein and a reduction in blood LDL-cholesterol concentrations $^{,(15)}$. The last published meta-analysis involved studies completed between 1996 and 2008, and examined mainly the effects of soya proteins on LDL-cholesterol ${ }^{(7)}$.

In the past 6 years, nine additional clinical trials (involving twelve comparisons and 668 people) on the effects of soya products on lipids have been completed. Based on the availability of more recent high-quality trials, the objective of this review was to re-examine the conclusion that soya protein has proven beneficial effects on blood cholesterol. We also assessed the effects of isoflavones and the combined effect of soya protein and isoflavones on blood cholesterol levels. Specifically, we sought to answer the following question: Does habitual consumption of soya products have a beneficial effect on blood cholesterol level, and if it does what are the predictors of this effect?

\section{Methods}

\section{Search strategy and study selection}

On 3 March 2014, we searched MEDLINE (through February 2014), CENTRAL (The Cochrane Controlled Clinical Trials Register) and the ClinicalTrials.gov website to identify RCT examining the effect of soya products on blood lipid profile. For the MEDLINE search, we used MeSH (major subject heading) terms ('soybeans' OR 'soybean oil' OR 'soybean proteins' OR 'soy isoflavones' OR 'soy milk') AND ('Cholesterol, HDL' OR 'Cholesterol, LDL' OR 'Triglycerides'). The search was limited to the criteria 'clinical trials', 'English', 'human' and 'last 10 years'. We limited to the last 10 years because the last published meta-analyses on this subject was completed in 2008. CENTRAL and the ClinicalTrials.gov website were searched using 'soy' or 'soybeans' as free terms without further restrictions applied to the search. Inspection of the reference list of all identified articles was also conducted. The latter method was repeated until all potentially relevant articles from these sources were identified. Retrieved studies were included if they met the following criteria: (a) were investigating dietary soya products; (b) had a randomised controlled parallel-arm or cross-over design; (c) included subjects aged 18 years and above; (d) reported 'end of intervention' mean and standard deviation values of lipid measurements for the active (intervention) and control groups; and (e) provided the intake amount of soya products. We a priori determined that unpublished materials and conference abstracts will be excluded from the review. One-day trials were also excluded because we wanted to report the effects of habitual intake of soya products. Care was taken not to include data from multiple publications of the same population. Furthermore, we excluded studies in which soya intake was mixed with other dietary treatments.

In a sub-study, we searched MEDLINE (through March 2014), CENTRAL and the ClinicalTrials.gov website to identify RCT examining the effect of soya isoflavone supplementation on blood lipid profile. We used the MeSH terms ('soy isoflavone' OR 'daidzein' OR 'genistein' OR 'glycitein') AND ('Cholesterol, HDL' OR 'Cholesterol, LDL' OR 'Triglycerides'). The search was limited to the criteria 'clinical trials', 'English' and 'human'.

\section{Data extraction and quality assessment}

Data were extracted by the lead author and subsequently reviewed by one of the co-authors for accuracy. Extracted data included the study characteristics (first author's name; year of publication; number and age of participants; study design; daily amount of soya product consumed in the active arm; duration of the study; health characteristics of the study population; and location of the study). We also extracted information on the final concentrations of plasma/serum TC, LDL-cholesterol, HDL-cholesterol and TAG in both treatment arms. When the requisite data were not available in the published paper, authors were emailed requesting the appropriate information. All the authors agreed on the eligibility criteria of the included studies. Quality of the studies was evaluated using the validated Jadad score instrument ${ }^{(16)}$ with criteria that included the following: randomisation, adequacy of sequence generation, double blinding and description of drop-outs. The maximum score obtainable was 5 .

\section{Data synthesis and statistical analysis}

The effect size used in this investigation was the 'difference in means' between the two treatment groups. We utilised plasma/ serum cholesterol concentrations obtained at the end of each intervention. Ideally, serum cholesterol concentrations are approximately $3 \%$ higher than the corresponding plasma concentrations $^{(17)}$, but because we were interested in mean differences within each study we analysed plasma and serum concentrations without adjustment for this difference. Studies that reported results in $\mathrm{mmol} / \mathrm{l}$ were converted to $\mathrm{mg} / \mathrm{dl}$ using the standard conversion factors (which was a division of the mmol/l value by 0.02586 for TC, LDL and HDL and by 0.01129 for TAG). Estimates of treatment effect on cholesterol in sub-groups defined according to study design features were also carried out. Additional analyses were performed according to the Cochrane Handbook for Systematic Reviews of Interventions ${ }^{(18)}$. 
Heterogeneity across studies was assessed by the Cochran's $Q$ test, and $P<0 \cdot 10$ was considered statistically significant for heterogeneity. The magnitude of heterogeneity was evaluated by the $I^{2}$ statistic (percentage of the variability in effect estimates that is due to heterogeneity rather than sampling error). Whenever the test for heterogeneity was statistically significant, the estimate of the difference was calculated using the random effects model, according to DerSimonian \& Laird $^{(19)}$. For the computation of pooled effects, each study was assigned a weight consisting of the reciprocal of its variance. Furthermore, we performed a metaregression to investigate whether there were any strong predictors of serum lipid changes. The included covariate variables were as follows: (1) initial lipid concentration; (2) duration of intake of soya products (weeks); (3) dose of soya protein consumed measured in grams per day; and (4) study quality (Jadad score). Each coefficient for the meta-regression analysis was estimated using restricted maximum likelihood and the corresponding variances were calculated using the 'Knapp-Hartung' variance estimator. Each meta-regression $F$ test was conducted at the significance level of $\alpha=0.05$, and all meta-regression analyses were performed using Stata/IC 13.1.
Data synthesis and other analyses were completed using Cochrane Collaboration Review Manager $5^{(20)}$ and Microsoft Office Excel 2010 package (Microsoft Corporation).

\section{Results}

A total of sixty-two articles met our inclusion criteria and their complete texts were downloaded and fully reviewed. A flow chart depicting the selection process is depicted in Fig. 1. Two studies were excluded because there was an inappropriate control group ${ }^{(21,22)}$; three because they were 1 -d trials ${ }^{(23-25)}$; five exclusions were due to the administration of a mixed test regimen ${ }^{(26-30)}$; and three studies were excluded due to lack of random assignment of the study groups ${ }^{(31-33)}$. Other studies were excluded for varying reasons (shown in Fig. 1). In all, thirty-five studies with fifty comparisons were included from our final analyses. Values used for the included studies represent the lipid measurements that correspond to the longest follow-up point. The observed $I^{2}$ statistic (percentage of the variability in effect estimates that is due to heterogeneity rather than sampling error) ranged from 92 to $99 \%$.

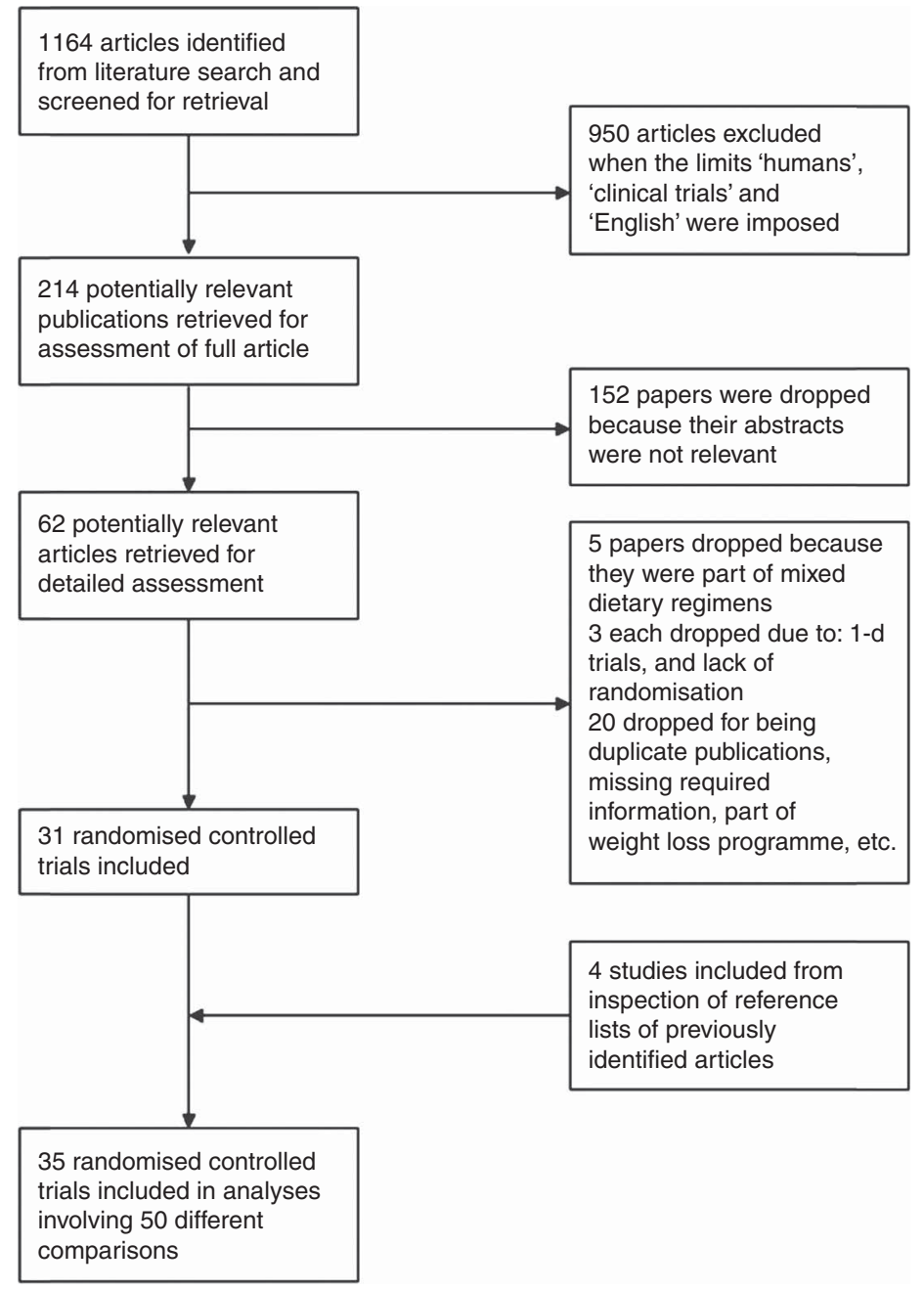

Fig. 1. Study selection process. 
In the sub-study examining the effect of soya isoflavone supplementation on blood lipids, our search produced thirty-two results, including four of the studies already included in our primary study. After exclusion of the twenty-one ineligible studies, we had eleven studies ${ }^{(34-44)}$ with fifteen comparison groups.

\section{Study and participant characteristics}

The characteristics of the included studies are presented in Table 1. Duration of the studies ranged from 4 weeks to 1 year, with many lasting about 8 weeks. Most RCT were double-blind, described an adequate method of sequence generation and reported details of drop-outs and withdrawals. Overall, twenty-four of the thirty-five studies obtained a Jadad score of $\geq 3$ (high quality).

A total of 2670 subjects (aged 28-83 years and $82 \%$ women) were included in the primary analyses. The average intake of soya protein was $30 \mathrm{~g} / \mathrm{d}$ (range: $14-50 \mathrm{~g} / \mathrm{d}$ ).

\section{Effects of soya on lipid concentration}

Intake of soya products resulted in a significant reduction in serum LDL-cholesterol concentration, -4.83 (95\% CI -7.34, -2.31) $\mathrm{mg} / \mathrm{dl}$ (Fig. 2). The effect quality test (Cochran's $Q$ ) did show significant heterogeneity, and thus the random effects model was used. We also observed statistically significant reduction in serum TAG, $-4.92(95 \%$ CI $-7.79,-2.04) \mathrm{mg} / \mathrm{dl}$ (Fig. 3), and TC concentrations, $-5 \cdot 33(95 \% \mathrm{CI}-8 \cdot 35,-2 \cdot 30) \mathrm{mg} /$ dl (Fig. 4). There was also a modest, but highly significant increase in serum HDL-cholesterol concentration, 1.40 (95\% CI $0.58,2 \cdot 23) \mathrm{mg} / \mathrm{dl}$ (Fig. 5).

For the sub-study in which only isoflavone supplementation was administered as the test regimen, all the results (LDL, HDL, TAG and TC) were non-significant.

\section{Sub-group analyses}

LDL reductions also appeared to be more marked in hypercholesterolaemic patients, -7.47 (95\% CI $-11.79,-3.16) \mathrm{mg} / \mathrm{dl}$, than in healthy subjects, $-2.96(95 \% \mathrm{CI}-5 \cdot 28,-0.65) \mathrm{mg} / \mathrm{dl}$. When natural soya products (soya milk, whole soyabeans and soya nuts) were used as the test regimen, we observed a substantial reduction in serum LDL levels, -11.06 (95\% CI -15.74, $-6.37) \mathrm{mg} / \mathrm{dl}$, as opposed to when 'processed' soya (soya extracts, supplements), -3.17 (95\% CI $-5 \cdot 75,-0.58) \mathrm{mg} / \mathrm{dl}$, was used. Intervention with soya protein alone seemed to exert a more positive effect on LDL and TC levels than intervention combining soya protein and isoflavone (Table 2). Studies adjudged to be of higher quality provided more precise estimates. Details of further analyses in sub-groups of studies defined by these study/participant characteristics are shown in Table 2. Sensitivity analyses conducted by excluding studies that used no control group ${ }^{(45)}$, used soya spread as the test $\operatorname{diet}^{(46)}$ or that did not have any washout period ${ }^{(47)}$ did not affect the results.

\section{Isoflavone sub-study}

The results of the sub-study that focused on the effect of isoflavone supplementation on LDL, HDL, TAG and TC were non-significant (Table 3). Sub-group analyses was also completed for each of these indices using design (cross-over $v$. parallel-arm), duration ( $\leq 12 v .>12$ weeks) and health status (Table 3).

\section{Predictors of the effect of soya on blood lipids}

The meta-regression analysis suggested that initial serum LDL, TAG and TC concentrations are strong predictors of the effect of soya on serum LDL, TAG and TC concentrations, respectively (Table 4; Fig. 6-8). Initial HDL concentration did not predict the effect of soya on blood HDL levels. Dose of soya protein, the duration of its consumption and the study quality (Jadad score) also did not predict the effect of soya on blood lipid levels (Table 4).

\section{Discussion}

Based on baseline lipid concentrations in the study population, our results show a significant 3\% reduction in serum LDL, $4 \%$ reduction in serum TAG and a $2 \%$ reduction in TC concentrations after an intervention with soya products for a period ranging from 4 to 52 weeks. We also observed a significant 3\% increase in serum HDL concentrations. This beneficial effect seemed stronger in individuals with a higher risk of $\mathrm{CHD}$ (hypercholesterolaemic, obese and diabetic subjects). It also appears that consumption of natural soya products is more effective in lowering serum cholesterol than intake of processed soya (e.g. soya protein extract preparations or supplements). LDL reduction was significant in the shorter-duration studies (4-8 weeks), whereas TAG reduction was only significant in the longer-lasting studies (10-52 weeks). Isoflavone supplementation only (i.e. without soya proteins) did not appear to significantly influence the serum lipid profile.

Various mechanisms have been suggested by which soya proteins may exert their lipid-lowering effects. Some have proposed the activation of LDL receptors by essential amino acids from soya protein ${ }^{(48)}$; others have discussed the possibility of a soya protein-based inhibition of endogenous cholesterol synthesis ${ }^{(49)}$. Water-soluble fibre and other components of soya may also reduce serum lipid levels ${ }^{(12)}$. Finally, it has been hypothesised that the substitution of soya for animal protein can result in lower saturated fat and cholesterol intakes, thereby indirectly resulting in a more favourable blood cholesterol levels ${ }^{(50)}$.

As casein has been reported to raise cholesterol levels, the relative increase in cholesterol concentration in the control group may be attributable to the casein content of the milk protein diet fed to the controls; however, when our analysis was restricted to the twenty-two comparisons where non-milk/noncasein-based diets were used as the control diet, the beneficial effect of the soya intervention on serum lipid was even more profound. Change in serum concentration was -6.37 (95\% CI $-10 \cdot 52,-2 \cdot 22) \mathrm{mg} / \mathrm{dl},-9 \cdot 39(95 \% \mathrm{CI}-12 \cdot 88,-5 \cdot 90) \mathrm{mg} / \mathrm{dl}$ and $-9.69(95 \% \mathrm{CI}-13.35,-6.04) \mathrm{mg} / \mathrm{dl}$ for LDL, TAG and TC, respectively.

Previous meta-analyses have reported on the hypolipidaemic effects of soya proteins ${ }^{(7,51,52)}$, soya isoflavones ${ }^{(53)}$ and soya proteins in combination with soya isoflavones ${ }^{(14)}$. Our results 
Table 1. Characteristics of the included studies

\begin{tabular}{|c|c|c|c|c|c|c|c|c|c|}
\hline \multirow[b]{2}{*}{ Author } & \multirow[b]{2}{*}{ Year } & \multirow[b]{2}{*}{ Design } & \multirow[b]{2}{*}{ Test/control } & \multirow[b]{2}{*}{ Participants } & \multirow[b]{2}{*}{ Duration (weeks) } & \multicolumn{2}{|l|}{ Diet } & \multicolumn{2}{|c|}{ Dose } \\
\hline & & & & & & Test & Control & Soya protein $(\mathrm{g} / \mathrm{d})$ & Isoflavones (mg) \\
\hline Afsaneh Bakhtiary & 2012 & Parallel & $25 / 25$ & Met S & 12 & Soya nuts & Nothing & 13.8 & $117 \cdot 2$ \\
\hline Afsaneh Bakhtiary & 2012 & Parallel & $25 / 25$ & Met S & 12 & Textured soya protein (TSP) & Nothing & 18.2 & 96.2 \\
\hline Liu ZM & 2010 & Parallel & $60 / 60$ & Postmenopausal, diabetic & 24 & Soya protein plus isoflavone powder & Milk protein & 15 & 100 \\
\hline Liu ZM - study 2 & 2010 & Parallel & $60 / 60$ & Postmenopausal, diabetic & 24 & Isoflavone powder & Milk protein & & 100 \\
\hline Santo Antonio & 2010 & Parallel & $11 / 9$ & Healthy & 4 & Soya protein isolate powder & Milk protein & 25 & 0.7 \\
\hline Santo Antonio - 2 & 2010 & Parallel & $10 / 9$ & Healthy & 4 & Soya protein isolate powder & Milk protein & 25 & $56 \cdot 2$ \\
\hline Campbell S C & 2010 & Parallel & $35 / 27$ & Postmenopausal & 52 & Soya snack bar or drink mix or cereal & Casein based & 25 & 60 \\
\hline Shidfar F & 2009 & Parallel & $21 / 21$ & Hyperlipidaemic/postmenopausal & 10 & Roasted soyabeans & Whey protein & 50 & 164 \\
\hline Pipe E & 2009 & $x$ & 29 & Diabetic type 2; postmenopausal & 8 & Soya protein beverage & Milk protein & 40 & 88 \\
\hline Tabibi H & 2009 & Parallel & $18 / 18$ & Peritoneal dialysis patients & 8 & Soya flour & Usual diet & 14 & \\
\hline Borodin EA & 2009 & $\mathrm{x}$ & 28 & Hyperlipidaemic & 8 & Soya protein isolate & $50 / 2$ & 30 & \\
\hline Thorp A & 2008 & $\mathrm{x}$ & 91 & Healthy & 6 & Soya protein & Dairy protein beverage & 24 & 71.4 \\
\hline Gardner CD & 2007 & $\mathrm{x}$ & 28 & Hypercholesterolaemic & 4 & Whole soyabean & Dairy milk & & 125 \\
\hline Gardner CD - 2 & 2007 & $\mathrm{x}$ & 28 & Hypercholesterolaemic & 4 & Soya protein isolate & Dairy milk & & 39 \\
\hline Hoie L & 2007 & Parallel & $28 / 28$ & Hypercholesterolaemic & 8 & $\begin{array}{l}\text { Native non-denatured isolated soya } \\
\text { protein }\end{array}$ & Milk protein & 25 & \\
\hline Hoie $L-2$ & 2007 & Parallel & $32 / 28$ & Hypercholesterolaemic & 8 & Conventional isolated soya protein & Milk protein & 25 & \\
\hline Clifton PM & 2007 & Parallel & $37 / 39$ & Healthy & 6 & Soya oil spread & Placebo spread & & \\
\hline Liao Fang-Hsuean & 2007 & Parallel & $15 / 15$ & Overweight & 8 & Soya meal & Traditional meal & 45 & \\
\hline Matthan $\mathrm{N}$ & 2007 & $\mathrm{x}$ & 28 & Hypercholesterolaemic & 6 & Whole soyabean & Animal protein & 37.5 & \\
\hline Matthan N-2 & 2007 & $\mathrm{x}$ & 28 & Hypercholesterolaemic & 6 & Soya flour & Animal protein & 37.5 & \\
\hline Matthan $\mathrm{N}-3$ & 2007 & $x$ & 28 & Hypercholesterolaemic & 6 & Soya milk & Animal protein & 37.5 & \\
\hline Ho S & 2007 & Parallel & $68 / 67$ & Postmenopausal & 52 & Isoflavone capsules & Maize starch capsules & & 80 \\
\hline Ho S -2 & 2007 & Parallel & $68 / 67$ & Postmenopausal & 52 & Isoflavone capsules & Maize starch capsules & & 40 \\
\hline Aubertin-Leheudre & 2007 & Parallel & $10 / 10$ & Obese, postmenopausal & 24 & Isoflavone capsules & Placebo & & 70 \\
\hline Allen & 2007 & Parallel & $93 / 98$ & Postmenopausal & 12 & Soya protein powder & Milk protein & 20 & 96 \\
\hline Azadbakht L & 2007 & $\mathrm{x}$ & 42 & Postmenopausal; Met S & 8 & Soya nut & $\begin{array}{l}\text { Animal protein - red } \\
\text { meat }\end{array}$ & & 102 \\
\hline Azadbakht $L-2$ & 2007 & $\mathrm{x}$ & 42 & Postmenopausal; MetS & 8 & TSP & $\begin{array}{l}\text { Animal protein - red } \\
\text { meat }\end{array}$ & 30 & 84 \\
\hline Welty F & 2007 & $\mathrm{x}$ & 48 & Postmenopausal & 8 & Unsalted soya nuts & TLC diet & 25 & 101 \\
\hline Welty $F-2$ & 2007 & $x$ & 12 & Postmenopausal and hypertensive & 8 & Unsalted soya nuts & TLC diet & 25 & 101 \\
\hline Hall WL & 2006 & $\mathrm{x}$ & 117 & Postmenopausal & 8 & Isoflavone-enriched cereal bars & Placebo cereal bars & & 50 \\
\hline Maesta N & 2006 & Parallel & $10 / 11$ & Postmenopausal & 16 & Soya protein powder supplement & Maltodextrin & 25 & 50 \\
\hline McVeigh B & 2006 & $x$ & 35 & Healthy & 8 & Soya protein powder supplement & Milk protein & 32 & 62 \\
\hline McVeigh B - 2 & 2006 & $\mathrm{x}$ & 35 & Healthy & 8 & Soya protein powder supplement & Milk protein & 32 & 2 \\
\hline Chen S & 2006 & Parallel & $13 / 13$ & $\begin{array}{l}\text { Hypercholesterolaemic on } \\
\text { haemodialysis }\end{array}$ & 12 & Soya protein beverage & Milk protein & 30 & \\
\hline Lukaczer D & 2005 & Parallel & $27 / 26$ & Postmenopausal & 12 & Soya protein + phytosterol & AHA standard diet & 30 & 34 \\
\hline Hermansen $\mathrm{K}$ & 2005 & Parallel & $49 / 51$ & Hypercholesterolaemic & 24 & Soya supplement (Abalon) & Casein & 30 & 100 \\
\hline Colacurci N & 2005 & Parallel & $29 / 28$ & Postmenopausal & 24 & Isoflavone tablets & Placebo tablet & & 60 \\
\hline Teede $\mathrm{H}$ & 2005 & Parallel & $19 / 21$ & Postmenopausal & 12 & Soya protein supplements & Casein & 40 & 118 \\
\hline Garrido A & 2005 & Parallel & $15 / 14$ & Postmenopausal & 12 & Isoflavone supplement capsule & Placebo capsule & & 100 \\
\hline Chen S & 2005 & Parallel & $10 / 9$ & Hyperlipidaemic on haemodialysis & 12 & Soya protein isolate beverage & Milk protein & 30 & \\
\hline Chen S - 2 & 2005 & Parallel & $8 / 10$ & Normolipidaemic on haemodialysis & 12 & Soya protein isolate beverage & Milk protein & 30 & \\
\hline Hoie L & 2005 & Parallel & $39 / 39$ & Hypercholesterolaemic & 8 & Soya protein supplement only & Milk protein & 25 & \\
\hline Hoie $L-2$ & 2005 & Parallel & $39 / 39$ & Hypercholesterolaemic & 8 & Soya protein supplement & Milk protein & 15 & \\
\hline Kreijkamp-Kaspers & 2004 & Parallel & $88 / 87$ & Postmenopausal & 52 & Soya protein supplement & Milk protein & 25.6 & 99 \\
\hline Wang $\mathrm{Y}$ & 2004 & $x$ & 20 & Hyperlipidaemic & 6 & Soya protein minus isoflavone & Milk and meat & 50 & 98 \\
\hline Wang $Y$ & 2004 & $x$ & 20 & Hyperlipidaemic & 6 & Soya protein and isoflavone & Milk and meat & 50 & 6 \\
\hline Wang $Y$ & 2004 & $\mathrm{x}$ & 20 & Hyperlipidaemic & 6 & Animal protein plus isoflavone & Milk and meat & & 98 \\
\hline Greany K & 2004 & $\hat{x}$ & 37 & $\begin{array}{l}\text { Normocholesterolaemic and } \\
\text { hypercholesterolaemic }\end{array}$ & 6 & Soya protein powder & Milk protein & 26 & 44 \\
\hline Meyer BJ & 2004 & $\mathrm{x}$ & 23 & $\begin{array}{l}\text { Hypercholesterolaemic and/or } \\
\text { hypertensive }\end{array}$ & 5 & Whole soyabean extract & Milk protein & 30 & 80 \\
\hline Teixeira S & 2004 & $\mathrm{x}$ & 14 & Diabetic/nephropathy & 8 & Soya protein powder & Casein & 47 & 94 \\
\hline
\end{tabular}




\begin{tabular}{|c|c|c|c|c|c|c|c|c|c|c|c|c|}
\hline \multirow{3}{*}{$\frac{\text { Study or sub-group }}{\text { Afsaneh B } 2012}$} & \multicolumn{3}{|c|}{ Soya } & \multicolumn{2}{|c|}{ Control } & \multirow[b]{2}{*}{ Total } & \multirow[b]{2}{*}{ Weight (\%) } & \multicolumn{2}{|c|}{ Mean difference } & \multirow{2}{*}{\multicolumn{2}{|c|}{$\begin{array}{c}\text { Mean difference } \\
\text { IV, random } 95 \% \mathrm{Cl}\end{array}$}} & \\
\hline & Mean & SD & Total & Mean & SD & & & \multicolumn{2}{|c|}{$\mathrm{IV}$, random $95 \% \mathrm{Cl}$} & & & \\
\hline & 131 & $25 \cdot 3$ & 25 & $151 \cdot 5$ & $29 \cdot 8$ & 25 & 1.5 & $-20 \cdot 50$ & $-35 \cdot 82,-5 \cdot 18$ & & & \\
\hline Afsaneh B 2012 - study 2 & $134 \cdot 5$ & $27 \cdot 1$ & 25 & $151 \cdot 5$ & $29 \cdot 8$ & 25 & $1 \cdot 4$ & $-17 \cdot 00$ & $-32 \cdot 79,-1 \cdot 21$ & & & \\
\hline Allen 2007 & $137 \cdot 3$ & $21 \cdot 3$ & 93 & $139 \cdot 6$ & $23 \cdot 7$ & 98 & $2 \cdot 7$ & $-2 \cdot 30$ & $-8.68,4.08$ & & & \\
\hline Aubertin-Leheudre 2007 & $127 \cdot 2$ & $22 \cdot 8$ & 10 & $131 \cdot 1$ & $20 \cdot 5$ & 10 & $1 \cdot 1$ & -3.90 & $-22 \cdot 90,15 \cdot 10$ & & & \\
\hline Azadbakht L 2007 & 118 & 3 & 42 & 134 & $3 \cdot 3$ & 42 & $3 \cdot 3$ & $-16 \cdot 00$ & $-17 \cdot 35,-14 \cdot 65$ & $=$ & & \\
\hline Azadbakht L 2007 - 2 & 127 & $2 \cdot 4$ & 42 & 134 & $3 \cdot 3$ & 42 & $3 \cdot 3$ & $-7 \cdot 00$ & $-8 \cdot 23,-5 \cdot 77$ & " & & \\
\hline Borodin EA 2009 & 0 & 0 & 0 & 0 & 0 & 0 & & & Not estimable & & & \\
\hline Campbell S C 2010 & $155 \cdot 3$ & $5 \cdot 9$ & 35 & 161 & $6 \cdot 6$ & 27 & $3 \cdot 2$ & $-5 \cdot 70$ & $-8.87,-2 \cdot 53$ & $=$ & & \\
\hline Chen S 2005 & 111 & $36 \cdot 1$ & 10 & $139 \cdot 1$ & 29 & 9 & 0.6 & $-28 \cdot 10$ & $-57 \cdot 42,1 \cdot 22$ & & & \\
\hline Chen S 2005 - 2 & $97 \cdot 8$ & $22 \cdot 8$ & 8 & $100 \cdot 7$ & $27 \cdot 1$ & 10 & 0.9 & $-2 \cdot 90$ & $-25 \cdot 96,20 \cdot 16$ & & & \\
\hline Chen S 2006 & $137 \cdot 7$ & $30 \cdot 2$ & 13 & 153.9 & $23 \cdot 6$ & 13 & 1.0 & $-16 \cdot 20$ & $-37 \cdot 03,4 \cdot 63$ & & & \\
\hline Clifton PM 2007 & $155 \cdot 8$ & $34 \cdot 8$ & 37 & $175 \cdot 2$ & $32 \cdot 1$ & 39 & 1.5 & $-19 \cdot 40$ & $-34 \cdot 47,-4 \cdot 33$ & & & \\
\hline Colacurci N 2005 & $146 \cdot 9$ & $15 \cdot 5$ & 29 & $139 \cdot 2$ & $11 \cdot 6$ & 28 & $2 \cdot 6$ & $7 \cdot 70$ & $0 \cdot 61,14 \cdot 79$ & & - & \\
\hline Gardner CD 2007 & 161 & 20 & 28 & 170 & 24 & 28 & 1.9 & $-9 \cdot 00$ & $-20.57,2.57$ & & & \\
\hline Gardner CD 2007 - 2 & 161 & 26 & 28 & 170 & 24 & 28 & $1 \cdot 7$ & $-9 \cdot 00$ & $-22 \cdot 11,4 \cdot 11$ & & & \\
\hline Garrido A 2005 & $143 \cdot 1$ & $11 \cdot 6$ & 15 & 119.9 & $15 \cdot 5$ & 14 & $2 \cdot 2$ & $23 \cdot 20$ & $13 \cdot 18,33 \cdot 22$ & & & \\
\hline Greany K 2004 & $132 \cdot 6$ & $1 \cdot 2$ & 37 & 128 & $1 \cdot 2$ & 37 & 3.3 & $4 \cdot 60$ & $4 \cdot 05,5 \cdot 15$ & & " & \\
\hline Hall W 2006 & 148.5 & $42 \cdot 9$ & 117 & $148 \cdot 1$ & $40 \cdot 2$ & 117 & $2 \cdot 1$ & 0.40 & $-10 \cdot 25,11.05$ & & & \\
\hline Hermansen K 2005 & $162 \cdot 4$ & $27 \cdot 1$ & 49 & $170 \cdot 1$ & $38 \cdot 7$ & 51 & $1 \cdot 7$ & $-7 \cdot 70$ & $-20 \cdot 75,5 \cdot 35$ & & & \\
\hline Ho S 2007 & $120 \cdot 2$ & $28 \cdot 2$ & 68 & $121 \cdot 8$ & 25 & 67 & $2 \cdot 3$ & $-1 \cdot 60$ & $-10 \cdot 59,7 \cdot 39$ & & & \\
\hline Ho S 2007 - 2 & $122 \cdot 7$ & $24 \cdot 5$ & 68 & $121 \cdot 8$ & 25 & 67 & $2 \cdot 4$ & 0.90 & $-7 \cdot 45,9.25$ & & & \\
\hline Hoie L 2005 & 157 & $18 \cdot 6$ & 39 & $167 \cdot 4$ & $22 \cdot 4$ & 39 & $2 \cdot 3$ & $-10 \cdot 40$ & $-19 \cdot 54,-1 \cdot 26$ & & & \\
\hline Hoie L 2005 - 2 & 157 & $25 \cdot 1$ & 39 & $167 \cdot 4$ & $22 \cdot 4$ & 39 & $2 \cdot 1$ & $-10 \cdot 40$ & $-20 \cdot 96,0 \cdot 16$ & & & \\
\hline Hoie LH 2007 & 147 & $20 \cdot 1$ & 28 & $156 \cdot 2$ & $29 \cdot 8$ & 28 & $1 \cdot 7$ & $-9 \cdot 20$ & $-22 \cdot 51,4 \cdot 11$ & & & \\
\hline Hoie LH 2007 - 2 & 152 & $22 \cdot 8$ & 32 & $156 \cdot 2$ & $29 \cdot 8$ & 28 & $1 \cdot 7$ & $-4 \cdot 20$ & $-17 \cdot 77,9 \cdot 37$ & & & \\
\hline Kreijkamp-Kaspers 2004 & $159 \cdot 8$ & $39 \cdot 3$ & 88 & $152 \cdot 8$ & $28 \cdot 1$ & 87 & $2 \cdot 2$ & $7 \cdot 00$ & $-3 \cdot 11,17 \cdot 11$ & & & \\
\hline Liao Fang-Hsuean 2007 & $95 \cdot 1$ & $16 \cdot 2$ & 15 & $110 \cdot 4$ & $20 \cdot 6$ & 15 & $1 \cdot 7$ & $-15 \cdot 30$ & $-28.56,-2.04$ & 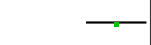 & & \\
\hline Liu ZM - 2010 - study 2 & 140 & $27 \cdot 5$ & 60 & $142 \cdot 3$ & $31 \cdot 7$ & 60 & $2 \cdot 1$ & $-2 \cdot 30$ & $-12.92,8.32$ & & & \\
\hline Liu ZM 2010 & $147 \cdot 7$ & $32 \cdot 9$ & 60 & $142 \cdot 3$ & $31 \cdot 7$ & 60 & 1.9 & $5 \cdot 40$ & $-6 \cdot 16,16 \cdot 96$ & & & \\
\hline Lukaczer D 2005 & $157 \cdot 8$ & $5 \cdot 4$ & 27 & $177 \cdot 1$ & 8.9 & 26 & $3 \cdot 1$ & $-19 \cdot 30$ & $-23 \cdot 28,-15 \cdot 32$ & $=$ & & \\
\hline Maesta N 2006 & $119 \cdot 5$ & $30 \cdot 7$ & 10 & $127 \cdot 8$ & $20 \cdot 3$ & 11 & 0.9 & $-8 \cdot 30$ & $-30 \cdot 79,14 \cdot 19$ & & & \\
\hline Matthan N 2007 & $137 \cdot 3$ & $23 \cdot 2$ & 28 & $140 \cdot 8$ & 22 & 28 & 1.9 & -3.50 & $-15 \cdot 34,8 \cdot 34$ & & & \\
\hline Matthan N 2007 - 2 & $140 \cdot 8$ & $20 \cdot 1$ & 28 & $140 \cdot 8$ & 22 & 28 & $2 \cdot 0$ & 0.00 & $-11.04,11.04$ & & & \\
\hline Matthan N 2007 - 3 & $134 \cdot 6$ & $22 \cdot 8$ & 28 & $140 \cdot 8$ & 22 & 28 & 1.9 & $-6 \cdot 20$ & $-17.94,5.54$ & $\longrightarrow$ & & \\
\hline McVeigh B 2006 & $102 \cdot 5$ & 1.9 & 35 & $110 \cdot 6$ & 1.9 & 35 & $3 \cdot 3$ & $-8 \cdot 10$ & $-8 \cdot 99,-7 \cdot 21$ & $\cdot$ & & \\
\hline McVeigh B 2006 - 2 & $104 \cdot 8$ & 1.9 & 35 & $110 \cdot 6$ & 1.9 & 35 & $3 \cdot 3$ & $-5 \cdot 80$ & $-6 \cdot 69,-4 \cdot 91$ &. & & \\
\hline Meyer B 2004 & $151 \cdot 6$ & $8 \cdot 1$ & 23 & $153 \cdot 9$ & $8 \cdot 1$ & 23 & 3.0 & $-2 \cdot 30$ & $-6 \cdot 98,2 \cdot 38$ & & & \\
\hline Pipe E 2009 & $107 \cdot 5$ & 5 & 29 & $112 \cdot 1$ & $4 \cdot 6$ & 29 & $3 \cdot 2$ & $-4 \cdot 60$ & $-7 \cdot 07,-2 \cdot 13$ & & & \\
\hline Santo Antonio 2010 & $113 \cdot 1$ & $14 \cdot 5$ & 11 & $102 \cdot 5$ & $12 \cdot 2$ & 9 & 1.9 & $10 \cdot 60$ & $-1 \cdot 10,22 \cdot 30$ & & & \\
\hline Santo Antonio 2010 - 2 & $102 \cdot 8$ & 23.3 & 10 & $102 \cdot 5$ & $12 \cdot 2$ & 9 & $1 \cdot 4$ & 0.30 & $-16 \cdot 19,16 \cdot 79$ & & & \\
\hline Shidfar F 2009 & 171.5 & $13 \cdot 1$ & 21 & $192 \cdot 1$ & $12 \cdot 5$ & 21 & $2 \cdot 5$ & $-20 \cdot 60$ & $-28 \cdot 34,-12 \cdot 86$ & & & \\
\hline Tabibi H 2009 & 89 & 30 & 18 & 86 & 33 & 18 & $1 \cdot 0$ & 3.00 & $-17 \cdot 60,23 \cdot 60$ & & & \\
\hline Teede H 2005 & $127 \cdot 6$ & $7 \cdot 7$ & 19 & $127 \cdot 6$ & $7 \cdot 7$ & 21 & 3.0 & 0.00 & $-4 \cdot 78,4 \cdot 78$ & & & \\
\hline Texeira S 2004 & $98 \cdot 6$ & $7 \cdot 7$ & 14 & $97 \cdot 1$ & $7 \cdot 3$ & 14 & $2 \cdot 9$ & 1.50 & $-4 \cdot 06,7 \cdot 06$ & & & \\
\hline Thorp A 2008 & $132 \cdot 6$ & $2 \cdot 7$ & 91 & $136 \cdot 5$ & $2 \cdot 7$ & 91 & $3 \cdot 3$ & -3.90 & $-4 \cdot 68,-3 \cdot 12$ & & & \\
\hline Wang Y 2004 & 186 & 34 & 20 & 196 & 35 & 20 & $1 \cdot 0$ & $-10 \cdot 00$ & $-31 \cdot 39,11 \cdot 39$ & & & \\
\hline Wang Y 2004 - 2 & 181 & 43 & 20 & 196 & 35 & 20 & 0.8 & $-15 \cdot 00$ & $-39.30,9.30$ & & & \\
\hline Wang Y 2004 - 3 & 192 & 39 & 20 & 196 & 35 & 20 & 0.9 & $-4 \cdot 00$ & $-26.97,18.97$ & & & \\
\hline Welty F 2007 & 142 & 31 & 48 & 143 & 32 & 48 & $1 \cdot 8$ & $-1 \cdot 00$ & $-13 \cdot 60,11 \cdot 60$ & & & \\
\hline Welty F 2007 - 2 & 146 & 46 & 12 & 164 & 57 & 12 & 0.3 & $-18 \cdot 00$ & $-59 \cdot 44,23 \cdot 44$ & & & \\
\hline Total $(95 \% \mathrm{Cl})$ & & & 1687 & & & 1679 & 100.0 & $-4 \cdot 83$ & $-7 \cdot 34,-2 \cdot 31$ & & & \\
\hline $\begin{array}{l}\text { Heterogeneity: } \tau^{2}=49 \cdot 46 \\
\text { Test for overall effect: } Z=3\end{array}$ & $\begin{array}{l}=1476 . \\
7(P=0\end{array}$ & $\begin{array}{l}26, \mathrm{df}= \\
.0002)\end{array}$ & $=48(r$ & 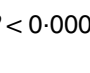 & & $=97 \%$ & & & -100 & -50 & & 50 \\
\hline
\end{tabular}

Fig. 2. Meta-analysis of the effect of soya on LDL-cholesterol. The sizes of the data markers indicate the weight of each study in the analysis. IV, inverse variance. Random-random effects model. Values are in $\mathrm{mg} / \mathrm{dl}$.

are consistent with analyses that report the cholesterol-lowering effects of soya protein. We, however, observed no effect of soya isoflavones on serum cholesterol levels and a reduced LDL-lowering effect in studies that administered soya proteins in combination with isoflavones (compared with studies that administered soya proteins alone). Soya protein plus isoflavone test diets, however, had a more positive effect on serum TAG concentrations.

Mean daily intake of soya protein is about $30 \mathrm{~g}$ in Japan, $20 \mathrm{~g}$ in Korea, $8 \mathrm{~g}$ in China and $<1 \mathrm{~g}$ in the $\mathrm{USA}^{(54,55)}$. The mean 


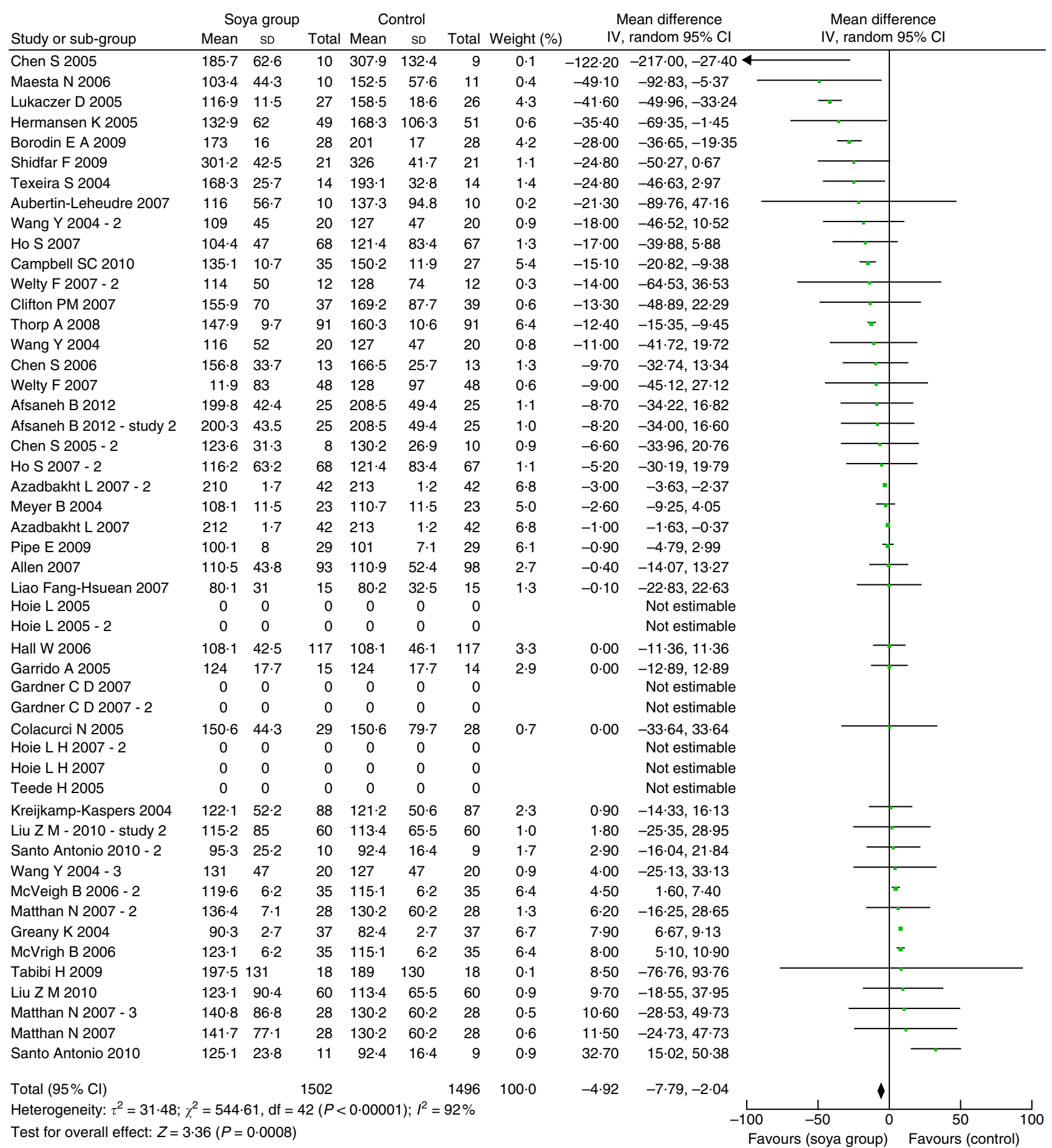

Fig. 3. Meta-analysis of the effect of soya on serum TAG. The sizes of the data markers indicate the weight of each study in the analysis. IV, inverse variance. Random-random effects model. Values are in $\mathrm{mg} / \mathrm{dl}$.

daily intake by participants in our analyses was $29.8 \mathrm{~g}$ (range: $14-50 \mathrm{~g}$ ). This potentially means that the cholesterolreducing effects of soya protein may not be realised by most soya consumers. It is important to note, however, that a dose-response effect of soya protein on cholesterol reduction was not observed in our analyses and is yet to be established.
As soyabeans are grown around the world under many different climatic conditions, there is a wide range of soyabean varieties. Unlike in Europe, GM soyabeans have become the predominant type grown in the Americas. When our results were stratified by study location, the studies completed in Europe, Asia and Australia showed highly significant positive effects. Conversely, the studies completed in North/South 


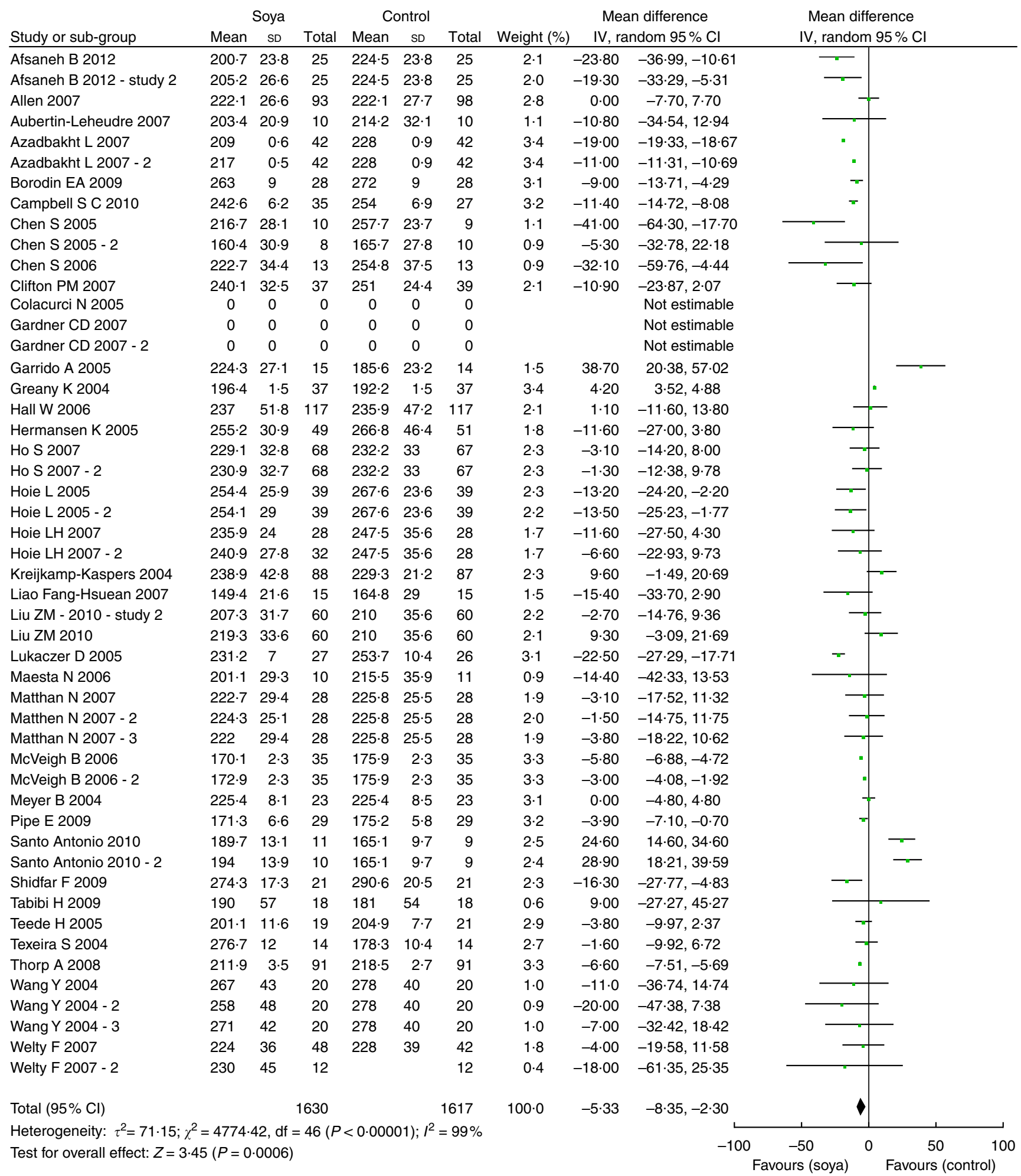

Fig. 4. Meta-analysis of the effect of soya on total cholesterol. The sizes of the data markers indicate the weight of each study in the analysis. IV, inverse variance. Random-random effects model. Values are in $\mathrm{mg} / \mathrm{dl}$.

America (where $>85 \%$ of soyabean produced is GM) showed non-significant results, except for a mild elevation of serum HDL.

In an earlier study, we observed varying effects of flavanols on serum lipids, depending on the matrix with which the flavanols were administered ${ }^{(56)}$. Consequently, in this analysis, we compared studies that used natural soya products (roasted soyabeans, soya nuts, etc.) with those that used soya extracts or tablets as the test regimen (Table 2). The LDL-cholesterollowering effect appeared to be three times stronger when 


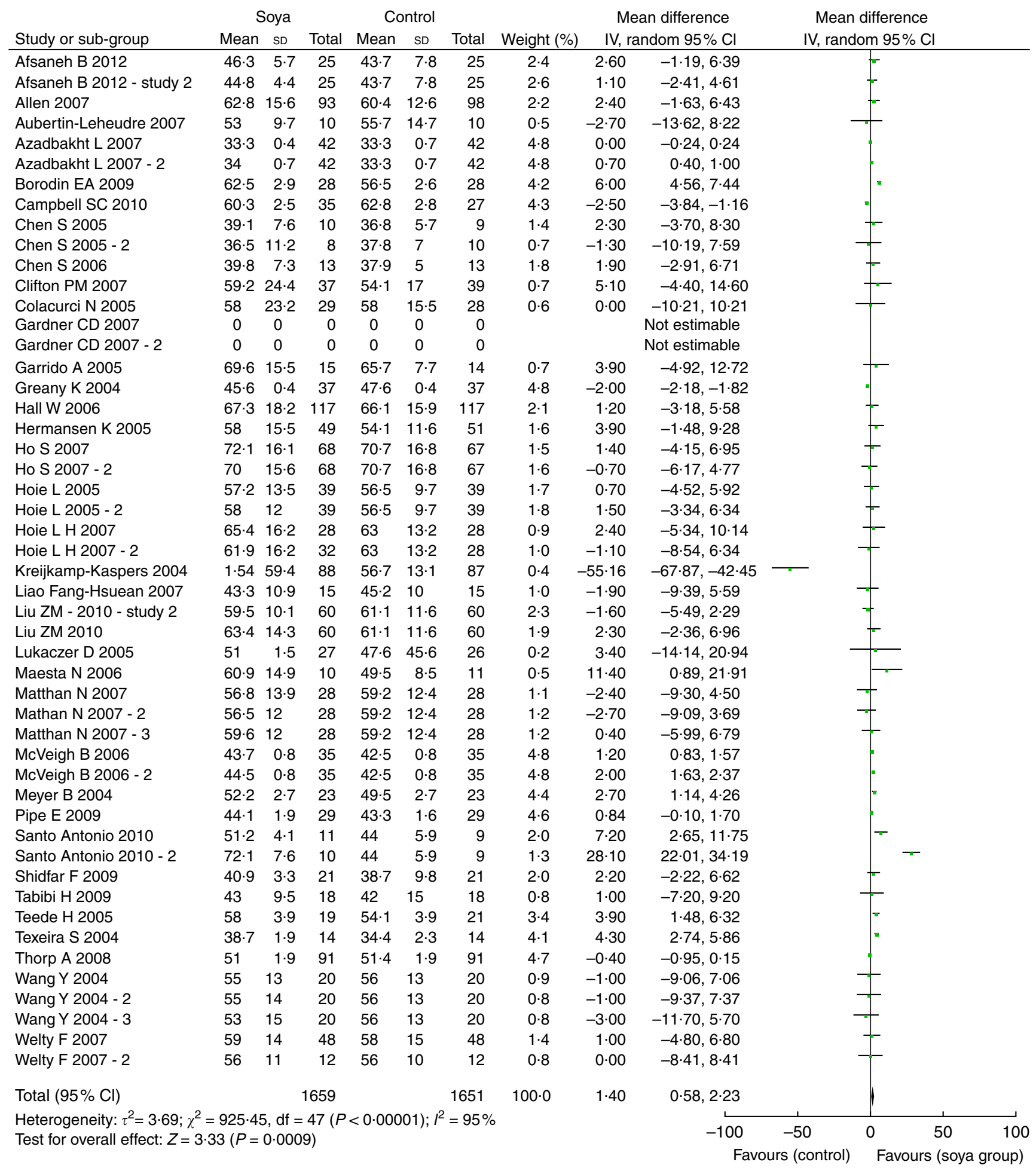

Fig. 5. Meta-analysis of the effect of soya on HDL-cholesterol. The sizes of the data markers indicate the weight of each study in the analysis. IV, inverse variance. Random-random effects model. Values are in $\mathrm{mg} / \mathrm{dl}$.

natural soya products were used. A potential explanation may be the differing levels of bioavailability of the active ingredients.

Soya isoflavones have a biological similarity to mammalian oestrogens, which have been shown to exert cholesterollowering effects in humans ${ }^{(57)}$. Our soya isoflavone sub-study revealed no effects of isoflavone supplementation on serum lipids. In their meta-analysis, Weggemans \& Trautwein ${ }^{(58)}$ also reported a lack of efficacy of soya isoflavones on changes in LDL or HDL-cholesterol. In contrast, another study has reported positive effects of isoflavone supplementation on cholesterol 
Table 2. Effects of soya proteins on serum lipids by study design, duration, location, health status and quality of study (Mean differences and $95 \%$ confidence intervals)

\begin{tabular}{|c|c|c|c|c|c|c|c|c|c|c|}
\hline & \multirow[b]{2}{*}{ Sub-group } & \multirow[b]{2}{*}{$\begin{array}{l}\text { Number of } \\
\text { comparisons }\end{array}$} & \multicolumn{2}{|c|}{ LDL (mg/dl) } & \multicolumn{2}{|c|}{$\mathrm{HDL}(\mathrm{mg} / \mathrm{dl})$} & \multicolumn{2}{|c|}{ TAG (mg/dl) } & \multicolumn{2}{|c|}{ Total cholesterol (mg/dl) } \\
\hline & & & $\begin{array}{c}\text { Mean } \\
\text { difference }\end{array}$ & $95 \% \mathrm{Cl}$ & $\begin{array}{l}\text { Mean } \\
\text { difference }\end{array}$ & $95 \% \mathrm{Cl}$ & $\begin{array}{l}\text { Mean } \\
\text { difference }\end{array}$ & $95 \% \mathrm{Cl}$ & $\begin{array}{l}\text { Mean } \\
\text { difference }\end{array}$ & $95 \% \mathrm{Cl}$ \\
\hline \multirow[t]{2}{*}{ Design } & Cross-over only & 21 & $-4 \cdot 87^{*}$ & $-8 \cdot 55,-1 \cdot 19$ & $1 \cdot 15^{*}$ & $0 \cdot 15,2 \cdot 16$ & $-2 \cdot 14$ & $-5.34,1.06$ & $-5 \cdot 46^{\star}$ & $-9.93,-1.00$ \\
\hline & Parallel only & 29 & $-4.95^{\star}$ & $-9.05,-0.84$ & 1.49 & $-0.96,3.95$ & $-8 \cdot 81^{*}$ & $-17.49,-0.21$ & $-5 \cdot 50^{*}$ & $-11 \cdot 15,0.16$ \\
\hline \multirow[t]{2}{*}{ Health status } & $\begin{array}{l}\text { Hypercholesterolaemic/diabetic/ } \\
\text { hypertensive }\end{array}$ & 32 & $-7 \cdot 47^{\star}$ & $-11 \cdot 79,-3 \cdot 16$ & $1 \cdot 15^{\star}$ & $0 \cdot 18,2 \cdot 13$ & $-3 \cdot 91^{*}$ & $-7.34,-0.47$ & $-9 \cdot 10$ & $-13.22,-4.98$ \\
\hline & Healthy & 18 & $-2 \cdot 96^{*}$ & $-5 \cdot 28,-0.65$ & $1.96^{*}$ & $0.48,3.44$ & $-5 \cdot 13$ & $-12 \cdot 70,2 \cdot 45$ & -2.02 & $-4.99,0.95$ \\
\hline \multirow[t]{2}{*}{ Duration } & Shorter duration (4-8 weeks) & 30 & $-5 \cdot 29^{\star}$ & $-8 \cdot 48,-2 \cdot 11$ & $1.74^{\star}$ & $0.77,2.72$ & -1.25 & $-4.37,1.86$ & $-4 \cdot 04^{\star}$ & $-7 \cdot 88,-0.20$ \\
\hline & Longer duration ( 10 weeks to 1 year) & 20 & $-4 \cdot 38$ & $-9.51,0.75$ & 0.15 & $-2 \cdot 38,2 \cdot 67$ & $-12.67^{\star}$ & $-21.45,-3.89$ & $-7.54^{\star}$ & $-13 \cdot 39,-1 \cdot 70$ \\
\hline \multirow[t]{4}{*}{ Test regimen } & Soya supplement & 38 & $-3 \cdot 17^{\star}$ & $-5.75,-0.58$ & $1.51^{*}$ & $0.47,2.55$ & $-5 \cdot 86^{\star}$ & $-10 \cdot 02,-1 \cdot 70$ & $-4 \cdot 22^{*}$ & $-7.34,-1.09$ \\
\hline & $\begin{array}{l}\text { Natural soya (nuts, milk, oil, whole bean, } \\
\text { flour) }\end{array}$ & 12 & $-11.06^{*}$ & $-15 \cdot 74,-6 \cdot 37$ & 1.06 & $-0.27,2 \cdot 39$ & $-1.03^{\star}$ & $-1.65,-0.40$ & $-9 \cdot 01^{*}$ & $-16 \cdot 78,-1 \cdot 25$ \\
\hline & Soya protein plus isoflavone & 22 & $-5 \cdot 88^{*}$ & $-9.80,-1.97$ & $1.42^{*}$ & $0.34,2.51$ & $-7 \cdot 12^{\star}$ & $-11 \cdot 75,-2 \cdot 48$ & $-4 \cdot 61^{*}$ & $-8.35,-0.86$ \\
\hline & Soya protein only & 13 & $-7 \cdot 62^{*}$ & $-11.45,-3.78$ & $1 \cdot 15$ & $-1.09,3.40$ & -7.48 & $-22 \cdot 77,7 \cdot 81$ & $-10 \cdot 03^{*}$ & $-14 \cdot 36,-5 \cdot 71$ \\
\hline \multirow[t]{2}{*}{ Jadad score } & $\operatorname{High}(\geq 3)$ & 31 & $-4 \cdot 17^{\star}$ & $-6 \cdot 14,-2 \cdot 19$ & $1.83^{*}$ & $0.76,2.90$ & $-6.95^{\star}$ & $-12 \cdot 83,-1.07$ & $-4 \cdot 27^{*}$ & $-6 \cdot 77,-1 \cdot 77$ \\
\hline & Low $(<3)$ & 19 & $-6 \cdot 61^{\star}$ & $-12.46,-0.75$ & 0.74 & $-0.50,1.98$ & $-2 \cdot 70$ & $-6 \cdot 70,1.30$ & $-7 \cdot 70^{\star}$ & $-13 \cdot 11,-2 \cdot 29$ \\
\hline \multirow[t]{2}{*}{ Location } & Americas & 23 & $-3 \cdot 21$ & $-7.04,0.63$ & $1.94^{\star}$ & $0.40,3.48$ & $-3 \cdot 23$ & $-9.01,2.56$ & $-1 \cdot 15$ & $-5.01,2 \cdot 71$ \\
\hline & Europe/Asia/Australia & 27 & $-6 \cdot 14^{\star}$ & $-9.25,-3.04$ & $1.29^{\star}$ & $0.38,2.19$ & $-6 \cdot 55^{\star}$ & $-9 \cdot 32,-3 \cdot 77$ & $-8 \cdot 62^{*}$ & $-11.81,-5.43$ \\
\hline
\end{tabular}

* Significant results

Table 3. Effects of soya isoflavone on serum lipids

(Mean differences and $95 \%$ confidence intervals)

\begin{tabular}{|c|c|c|c|c|c|c|c|c|c|}
\hline & \multirow[b]{2}{*}{ Sub-group } & \multicolumn{2}{|c|}{ LDL (mg/dl) } & \multicolumn{2}{|c|}{$\mathrm{HDL}(\mathrm{mg} / \mathrm{dl})$} & \multicolumn{2}{|c|}{ TAG (mg/dl) } & \multicolumn{2}{|c|}{ Total cholesterol (mg/dl) } \\
\hline & & Mean difference & $95 \% \mathrm{Cl}$ & Mean difference & $95 \% \mathrm{Cl}$ & Mean difference & $95 \% \mathrm{Cl}$ & Mean difference & $95 \% \mathrm{Cl}$ \\
\hline All 15 studies & & -0.48 & $-3 \cdot 42,2.46$ & 0.97 & $-2.93,1.00$ & 2.49 & $-5.78,10.77$ & -1.08 & $-4.69,2.53$ \\
\hline \multirow{2}{*}{ Design } & Cross-over only & $-5 \cdot 06^{\star}$ & $-7.45,-2.67$ & 0.88 & $0.50,1.25$ & 2.66 & $-0.93,4.39$ & -3.82 & $-5.86,-1.79$ \\
\hline & Parallel only & 2.48 & $-2.43,7.39$ & -3.65 & $-8.38,1.08$ & -3.63 & $-27 \cdot 63,20 \cdot 38$ & 0.86 & $-10 \cdot 48,12 \cdot 21$ \\
\hline \multirow[t]{2}{*}{ Health status } & Hypercholesterolaemic & $-6 \cdot 05^{*}$ & $-8.42,-3.68$ & $1.05^{*}$ & $0.54,1.56$ & 0.75 & $-7.55,9.05$ & $-5 \cdot 08^{\star}$ & $-7.03,-3.12$ \\
\hline & Healthy & 1.31 & $-2 \cdot 83,5 \cdot 44$ & $-2 \cdot 88$ & $-6 \cdot 05,0.30$ & 4.57 & $-6 \cdot 99,16 \cdot 12$ & 0.54 & $-5 \cdot 34,6 \cdot 43$ \\
\hline \multirow[t]{2}{*}{ Duration } & Shorter duration ( $\leq 12$ weeks) & $-1 \cdot 34$ & $-6 \cdot 39,3.71$ & $-1 \cdot 22$ & $-4 \cdot 95,2 \cdot 50$ & 14.29 & $-2 \cdot 65,31 \cdot 23$ & 0.41 & $-6 \cdot 21,7 \cdot 03$ \\
\hline & Longer duration ( $>12$ weeks) & 0.01 & $-3.71,3.72$ & -0.33 & $-2 \cdot 41,1 \cdot 75$ & 0.12 & $-5 \cdot 25,5 \cdot 49$ & $-4 \cdot 35^{*}$ & $-7.18,-1.53$ \\
\hline
\end{tabular}

* Significant results. 
Table 4. Meta-regression - predictors of the effects of soya on serum lipids (Coefficients and their standard errors)

\begin{tabular}{|c|c|c|c|c|c|c|c|c|c|c|c|c|}
\hline & \multicolumn{3}{|c|}{ LDL (mg/dl) } & \multicolumn{3}{|c|}{$\mathrm{HDL}(\mathrm{mg} / \mathrm{dl})$} & \multicolumn{3}{|c|}{ TAG (mg/dl) } & \multicolumn{3}{|c|}{ Total cholesterol (mg/dl) } \\
\hline & Coefficient & $\mathrm{SE}$ & $P$ & Coefficient & SE & $P$ & Coefficient & SE & $P$ & Coefficient & $\mathrm{SE}$ & $P$ \\
\hline Initial lipid concentration & $-0 \cdot 13^{*}$ & $0.05^{*}$ & $0.01^{*}$ & 0.02 & 0.05 & 0.74 & $-0 \cdot 19^{*}$ & $0.05^{*}$ & $<0.01^{*}$ & $-0 \cdot 19^{*}$ & $0.05^{*}$ & $<0.01^{*}$ \\
\hline Duration of study & 0.12 & 0.11 & 0.25 & -0.09 & 0.05 & 0.08 & -0.26 & 0.24 & 0.29 & -0.01 & 0.19 & 0.96 \\
\hline Dose of test diet & -0.12 & 0.14 & 0.38 & 0.01 & 0.05 & 0.79 & -0.30 & 0.31 & 0.35 & -0.19 & 0.20 & 0.35 \\
\hline
\end{tabular}

*Significant results.

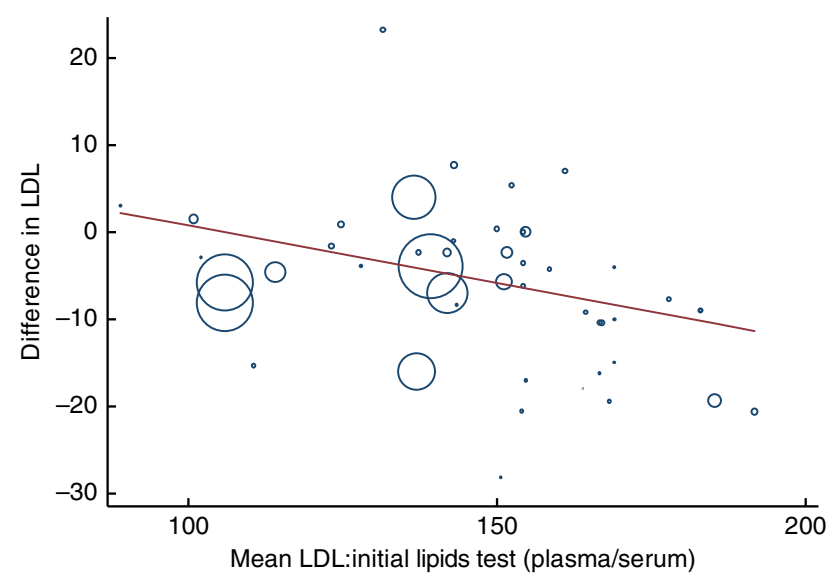

Fig. 6. Meta-regression plot of the effect of initial LDL concentration on soya's effect on LDL-cholesterol. Values are in $\mathrm{mg} / \mathrm{dl}$.

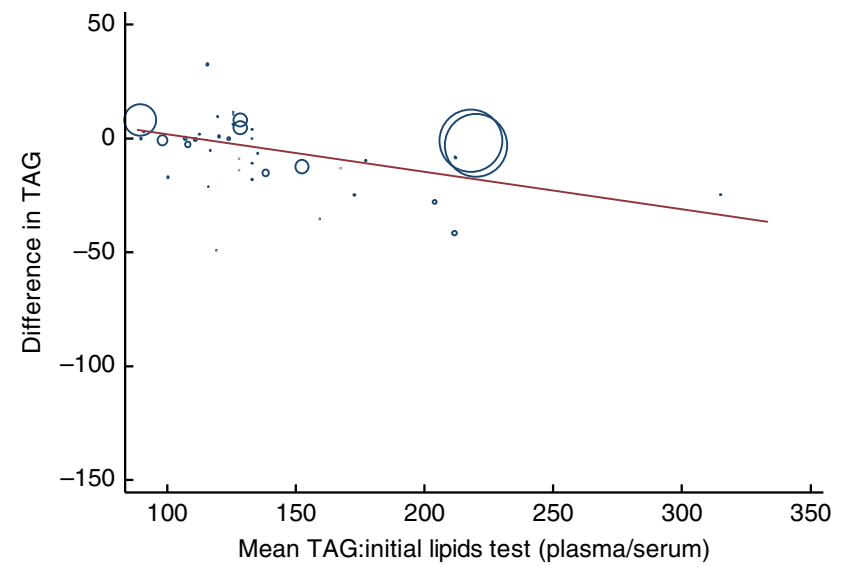

Fig. 7. Meta-regression plot of the effect of initial TAG concentration on soya's effect on blood TAG level. Values are in $\mathrm{mg} / \mathrm{dl}$.

and endothelial function ${ }^{(39)}$. The varying conclusions on the effect of isoflavones may be in part due to the process by which the isoflavones were extracted ${ }^{(59)}$. Mean isoflavone consumption is $11-47 \mathrm{mg} / \mathrm{d}$ in Asian countries and $1-2 \mathrm{mg} / \mathrm{d}$ in Western countries $^{(60,61)}$, but the mean daily isoflavone consumption in the included studies was $76 \mathrm{mg}$.

Although we observed a high level of heterogeneity, we are still confident in the conclusions of these analyses, as our observations are consistent with many of the other previously published reports.

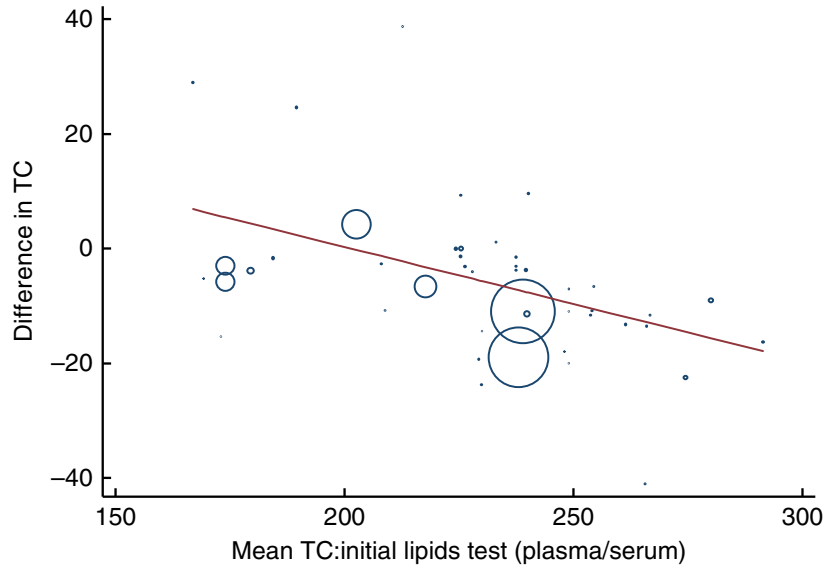

Fig. 8. Meta-regression plot of the effect of initial total concentration (TC) concentration on soya's effect on blood TC level. Values are in $\mathrm{mg} / \mathrm{dl}$.

In conclusion, our findings showed that an intervention with soya proteins increases serum HDL concentration and lowers serum TAG, LDL and TC concentrations. No effect of isoflavones was observed on serum lipids, and natural soya products appear to have a stronger hypolipidaemic effect on serum cholesterol than soya supplements. Finally, initial LDL, TAG and TC concentrations seem to be strong predictors of the effect of soya on blood lipid levels.

\section{Acknowledgements}

During the last 3 years, O. A. T. reports that he has received an investigator-initiated grant from the National Institutes of Health; L. D. reports that he has received investigator-initiated grants from the National Institutes of Health, GlaxoSmithKline, Amarin Pharma Inc., California Walnut Commission and Merck, and has received travel re-imbursement from the International Nut \& Dried Fruit Council Inc.; J. M. G. reports that he has received investigatorinitiated grants from the National Institutes of Health, the Veterans Administration, Amgen and pills and packaging from Pfizer for a research study, and has served as a consultant to Bayer.

L. D. and O. A. T. conceived the study and are responsible for data integrity and accuracy of data analyses. O. A. T. and T. A. O. drafted the manuscript, and along with L. D. have the primary responsibility for final content. O. A. T., A. Y. and T. A. O. completed the statistical analyses; J. M. G. reviewed the manuscript for its scientific content. All the authors have read and approved this final draft.

The authors have no conflict of interest to declare. 


\section{References}

1. World Health Organization (2002) The World Health Report 2002; Reducing Risks, Promoting Healthy Life. Geneva: WHO.

2. Sirtori CR, Anderson JW \& Arnoldi A (2007) Nutritional and nutraceutical considerations for dyslipidemia. Future Med 2, 313-339.

3. Katan MB, Grundy SM, Jones P, et al. (2003) Efficacy and safety of plant stanols and sterols in the management of blood cholesterol levels. Mayo Clin Proc 78, 965-978.

4. Anderson JW \& Konz EC (2001) Obesity and disease management: effects of weight loss on comorbid conditions. Obes Res $9,326 \mathrm{~S}-334 \mathrm{~S}$.

5. Ashen MD \& Blumenthal RS (2005) Low HDL cholesterol levels. $N$ Engl J Med 353, 1252-1260.

6. Ginsberg HN (1997) Is hypertriglyceridemia a risk factor for atherosclerotic cardiovascular disease? A simple question with a complicated answer. Ann Intern Med 126, 912-914.

7. Anderson JW \& Bush HM (2011) Soy protein effects on serum lipoproteins: a quality assessment and meta-analysis of randomized, controlled studies. J Am Coll Nutr 30, 79-91.

8. Sacks FM, Lichtenstein A, Van Horn L, et al. (2006) Soy protein, isoflavones, and cardiovascular health: an American Heart Association Science Advisory for professionals from the Nutrition Committee. Circulation 113, 1034-1044.

9. Ferdowsian HR \& Barnard ND (2009) Effects of plant-based diets on plasma lipids. Am J Cardiol 104, 947-956.

10. Anderson JW, Johnstone BM \& Cook-Newell ME (1995) Metaanalysis of the effects of soy protein intake on serum lipids. $N$ Engl J Med 333, 276-282.

11. Food \& Administration D (1999) Food labeling health claims; soy protein and coronary heart disease. Fed Regist 64, 57699-57733.

12. Erdman JW (2000) Soy protein and cardiovascular disease: a statement for healthcare professionals from the Nutrition Committee of the AHA. Circulation 102, 2555-2559.

13. Xiao CW (2008) Health effects of soy protein and isoflavones in humans. J Nutr 138, 1244S-1249S.

14. Zhan S \& Ho SC (2005) Meta-analysis of the effects of soy protein containing isoflavones on the lipid profile. Am J Clin Nutr 81, 397-408.

15. EFSA Panel on Dietetic Products Nutrition and Allergies (2012) Scientific opinion on the substantiation of a health claim related to isolated soy protein and reduction of blood LDLcholesterol concentrations pursuant to Article 14 of Regulation (EC) No 1924/2006. EFSA Journal 10, 2555.

16. Jadad AR, Moore RA, Carroll D, et al. (1996) Assessing the quality of reports of randomized clinical trials: is blinding necessary? Control Clin Trials 17, 1-12.

17. Lipid Research Clinics Laboratory Methods Committee (1977) Cholesterol and triglyceride concentrations in serum/ plasma pairs. Clin Chem 23, 60-63.

18. Higgins J \& Green S (2010) Cochrane Handbook for Systematic Reviews of Interventions Version 5.0. 2. The Cochrane Collaboration, 2009. Chichester: John Wiley.

19. DerSimonian R \& Laird N (1986) Meta-analysis in clinical trials. Control Clin Trials 7, 177-188.

20. Collaboration RTC (2008) Review Manager (RevMan). 5.0. Copenhagen, The Nordic Cochrane Centre, The Cochrane Collaboration.

21. Engelman HM, Alekel DL, Hanson LN, et al. (2005) Blood lipid and oxidative stress responses to soy protein with isoflavones and phytic acid in postmenopausal women. Am J Clin Nutr 81, 590-596.

22. Ahn-Jarvis J, Clinton SK, Riedl KM, et al. (2012) Impact of food matrix on isoflavone metabolism and cardiovascular biomarkers in adults with hypercholesterolemia. Food Funct 3, 1051-1058.

23. Campbell CG, Brown BD, Dufner D, et al. (2006) Effects of soy or milk protein during a high-fat feeding challenge on oxidative stress, inflammation, and lipids in healthy men. Lipids 41, 257-265.

24. Hall WL, Formanuik NL, Harnpanich D, et al. (2008) A meal enriched with soy isoflavones increases nitric oxide-mediated vasodilation in healthy postmenopausal women. J Nutr 138, $1288-1292$.

25. Hanwell HE, Kay CD, Lampe JW, et al. (2009) Acute fish oil and soy isoflavone supplementation increase postprandial serum ( $n$-3) polyunsaturated fatty acids and isoflavones but do not affect triacylglycerols or biomarkers of oxidative stress in overweight and obese hypertriglyceridemic men. $J$ Nutr 139, 1128-1134.

26. Matthan NR, Welty FK, Barrett PHR, et al. (2004) Dietary hydrogenated fat increases high-density lipoprotein apoA-I catabolism and decreases low-density lipoprotein apoB-100 catabolism in hypercholesterolemic women. Arterioscler Thromb Vasc Biol 24, 1092-1097.

27. Jenkins DJ, Kendall CW, Marchie A, et al. (2005) Direct comparison of a dietary portfolio of cholesterol-lowering foods with a statin in hypercholesterolemic participants. Am J Clin Nutr 81, 380-387.

28. Verhoeven MO, Teerlink T, Kenemans P, et al. (2007) Effects of a supplement containing isoflavones and Actaea racemosa L. on asymmetric dimethylarginine, lipids, and C-reactive protein in menopausal women. Fertil Steril 87, 849-857.

29. Weidner C, Krempf M, Bard JM, et al. (2008) Cholesterol lowering effect of a soy drink enriched with plant sterols in a French population with moderate hypercholesterolemia. Lipids Health Dis 7, 35-42.

30. Rideout TC, Chan Y-M, Harding SV, et al. (2009) Low and moderate-fat plant sterol fortified soymilk in modulation of plasma lipids and cholesterol kinetics in subjects with normal to high cholesterol concentrations: report on two randomized crossover studies. Lipids Health Dis $\mathbf{8}, 45$.

31. Jenkins DJ, Kendall CW, Nguyen TH, et al. (2008) Effect of plant sterols in combination with other cholesterollowering foods. Metabolism 57, 130-139.

32. Torres N, Guevara-Cruz M, Granados J, et al. (2009) Reduction of serum lipids by soy protein and soluble fiber is not associated with the ABCG5/G8, apolipoprotein E, and apolipoprotein A1 polymorphisms in a group of hyperlipidemic Mexican subjects. Nutr Res 29, 728-735.

33. Lobato LP, Iakmiu Camargo Pereira AE, Lazaretti MM, et al. (2012) Snack bars with high soy protein and isoflavone content for use in diets to control dyslipidaemia. Int J Food Sci Nutr 63, 49-58.

34. Hodgson JM, Puddey IB, Beilin LJ, et al. (1998) Supplementation with isoflavonoid phytoestrogens does not alter serum lipid concentrations: a randomized controlled trial in humans. J Nutr 128, 728-732.

35. Merz-Demlow BE, Duncan AM, Wangen KE, et al. (2000) Soy isoflavones improve plasma lipids in normocholesterolemic, premenopausal women. Am J Clin Nutr 71, 1462-1469.

36. Wangen KE, Duncan AM, Xu X, et al. (2001) Soy isoflavones improve plasma lipids in normocholesterolemic and mildly hypercholesterolemic postmenopausal women. Am J Clin Nutr 73, 225-231.

37. Uesugi T, Fukui Y \& Yamori Y (2002) Beneficial effects of soybean isoflavone supplementation on bone metabolism and serum lipids in postmenopausal Japanese women: a four-week study. J Am Coll Nutr 21, 97-102. 
38. Cheng SY, Shaw NS, Tsai KS, et al. (2004) The hypoglycemic effects of soy isoflavones on postmenopausal women. $J$ Womens Health 13, 1080-1086.

39. Colacurci N, Chiantera A, Fornaro F, et al. (2005) Effects of soy isoflavones on endothelial function in healthy postmenopausal women. Menopause 12, 299-307.

40. Garrido A, la Maza D, Pia M, et al. (2006) Soy isoflavones affect platelet thromboxane $\mathrm{A}_{2}$ receptor density but not plasma lipids in menopausal women. Maturitas 54, 270-276.

41. Hall WL, Vafeiadou K, Hallund J, et al. (2006) Soy-isoflavoneenriched foods and markers of lipid and glucose metabolism in postmenopausal women: interactions with genotype and equol production. Am J Clin Nutr 83, 592-600.

42. Ho SC, Chen YM, Ho SS, et al. (2007) Soy isoflavone supplementation and fasting serum glucose and lipid profile among postmenopausal Chinese women: a double-blind, randomized, placebo-controlled trial. Menopause 14, 905-912.

43. Rios DRA, Rodrigues ET, Cardoso APZ, et al. (2008) Lack of effects of isoflavones on the lipid profile of Brazilian postmenopausal women. Nutrition 24, 1153-1158.

44. Qin Y, Shu F, Zeng Y, et al. (2014) Daidzein supplementation decreases serum triglyceride and uric acid concentrations in hypercholesterolemic adults with the effect on triglycerides being greater in those with the GA compared with the GG genotype of ESR- $\beta$ RsaI. J Nutr 144, 49-54.

45. Bakhtiary A, Yassin Z, Hanachi P, et al. (2012) Effects of soy on metabolic biomarkers of cardiovascular disease in elderly women with metabolic syndrome. Arch Iran Med 15, 462-468.

46. Clifton P, Mano M, Duchateau G, et al. (2008) Dose-response effects of different plant sterol sources in fat spreads on serum lipids and C-reactive protein and on the kinetic behavior of serum plant sterols. Eur J Clin Nutr 62, 968-977.

47. Meyer BJ, Larkin TA, Owen AJ, et al. (2004) Limited lipidlowering effects of regular consumption of whole soybean foods. Ann Nutr Metab 48, 67-78.

48. Gianazza E, Lovati M, Manzoni C, et al. (1998) Reduction of serum cholesterol by soy proteins: clinical experience and potential molecular mechanisms. Nutr Metab Cardiovasc Dis 8, 334-340.

49. Tham DM, Gardner CD \& Haskell WL (1998) Potential health benefits of dietary phytoestrogens: a review of the clinical, epidemiological, and mechanistic evidence 1. J Clin Endocrinol Metab 83, 2223-2235.

50. Lichtenstein AH (1998) Soy protein, isoflavones and cardiovascular disease risk. J Nutr 128, 1589-1592.

51. Reynolds K, Chin A, Lees KA, et al. (2006) A meta-analysis of the effect of soy protein supplementation on serum lipids. Am J Cardiol 98, 633-640.

52. Harland JI \& Haffner TA (2008) Systematic review, metaanalysis and regression of randomised controlled trials reporting an association between an intake of circa $25 \mathrm{~g}$ soya protein per day and blood cholesterol. Atherosclerosis 200, $13-27$.

53. Taku K, Umegaki K, Sato Y, et al. (2007) Soy isoflavones lower serum total and LDL cholesterol in humans: a metaanalysis of 11 randomized controlled trials. Am J Clin Nutr $\mathbf{8 5}$, $1148-1156$

54. Ho SC, Woo JL, Leung SS, et al. (2000) Intake of soy products is associated with better plasma lipid profiles in the Hong Kong Chinese population. J Nutr 130, 2590-2593.

55. Nagata C (2000) Ecological study of the association between soy product intake and mortality from cancer and heart disease in Japan. Int J Epidemiol 29, 832-836.

56. Tokede O, Gaziano J \& Djoussé L (2011) Effects of cocoa products/dark chocolate on serum lipids: a meta-analysis. Eur J Clin Nutr 65, 879-886.

57. Rossouw JE (1999) Hormone replacement therapy and cardiovascular disease. Curr Opin Lipidol 10, 429-434.

58. Weggemans R \& Trautwein E (2003) Relation between soy-associated isoflavones and LDL and HDL cholesterol concentrations in humans: a meta-analysis. Eur J Clin Nutr $\mathbf{5 7}$, 940-946.

59. Clarkson TB \& Anthony MS (1998) Phytoestrogens and coronary heart disease. Baillieres Clin Endocrinol Metab 12, 589-604.

60. Arai Y, Watanabe S, Kimira M, et al. (2000) Dietary intakes of flavonols, flavones and isoflavones by Japanese women and the inverse correlation between quercetin intake and plasma LDL cholesterol concentration. J Nutr 130, 2243-2250.

61. de Kleijn MJ, van der Schouw YT, Wilson PW, et al. (2001) Intake of dietary phytoestrogens is low in postmenopausal women in the United States: the Framingham study (1-4). J Nutr 131, 1826-1832. 